\title{
PARAMETERS AFFECTING THE STRUCTURAL ANALYSIS OF A TUNNEL STRUCTURE EXPOSED TO FIRE
}

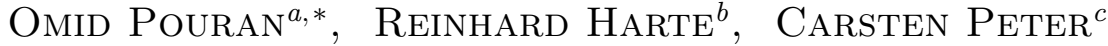 \\ ${ }^{a}$ Structural Engineering, Institute for Statics and Dynamics of Structures, Bergische Universität Wuppertal, \\ Wuppertal, Germany \\ ${ }^{b}$ Structural Engineering, Institute for Statics and Dynamics of Structures, Bergische Universität Wuppertal, \\ Wuppertal, Germany. Kraetzig \& Partner Engineering Consultants, Bochum, Germany \\ c IMM Maidl $\&$ Maidl Engineering Consultants, Bochum, Germany \\ * corresponding author: pouran@uni-wuppertal.de
}

\begin{abstract}
Behaviour of cut-and-cover tunnels exposed to fire should be analysed by using a realistic structural model that takes account of mechanical and thermal effects on the structure. This has been performed with the aid of Finite Element (FE) software package called SOFiSTiK in parallel, for two types of elements as a scope of research project financed by the German Bundesanstalt für Straßenwesen BAST. Since the stiffness of the structure at elevated temperatures is highly affected, a realistic model of structural behaviour of the tunnel could be only achieved by considering the nonlinear analysis of the structure. This has been performed for a 2-cell cut and cover tunnel by taking account of simultaneous reduction of stiffness and strength and the time-dependent increasing indirect effects due to axial constraints and temperature gradients induced by elevated temperatures. The thermal analyses have been performed and the effects were implemented into the structural model by the multi-layered strain model. The stress-strain model proposed by EN 1992-1-2 is implemented for the elevated temperature. Since there was sufficient amount of Polypropylene fibres in the concrete mixtures, modelling of spalling was excluded from the analysis. The critical corresponding stresses and material behaviour are compared and interpreted at different time stages. The main parameters affecting the accuracy and convergence of the results of structural analysis for the used model are identified: defining a realistic fire action, using concrete material model fulfilling the requirements of fire situation in tunnels, defining appropriate time intervals for load implementations. These parameters along with other parameters, which influence the results to a lesser degree, are identified and investigated in this paper.
\end{abstract}

KEYWORDs: Cut-and-cover, tunnel, fire, thermal effects, structural analysis, accidental situation.

\section{INTRODUCTION}

In the event of fire, structural behaviour of road tunnels are affected by imposed thermal effects to high extent and this might, consequently, result in failure of the structure. This risk can be minimized by means of appropriate fire design, which provides sufficient passive fire protection for the structure.

Using an advanced method proposed by EN 19921-2 1 to analyse and design such structures, the following three main areas should be taken into account:

- Determination of fire action for the specified project,

- Using realistic material model for the concrete exposed to high temperatures,

- Defining a thermo-mechanical model which takes account of indirect-thermally induced effects corresponding to the specified fire action and the strength reductions due to temperature rise simultaneously.

In Germany, the nominal fire exposure curve adopted in for tunnel structures is called ZTV-ING fire exposure curve [2]. This can be assumed as fire action applied to the compartmented tunnel structure for accidental fire design situation. Further, regarding the material behaviour of reinforced concrete structures, spalling of concrete is an important phenomenon. This implies reduction of cross section thickness and, as a consequence, decrease of concrete cover, which may expose the reinforcement directly to the fire. To avoid spalling, in Germany, Polypropylene fibres (PP fibres) are usually used to improve the concrete for both new road and railway tunnels. The addition of PP fibres, verifiably, reduces the inner pore pressure in the concrete and by this decreases the risk and impact of concrete spalling [3], as various small and large-scale fire tests have shown. The stressstrain curve proposed by EN 1992-1-2 [1] for concrete exposed to elevated temperatures is for the concrete without $\mathrm{PP}$ fibres and the heating rate between 2 to $50 \mathrm{~K} \cdot \mathrm{min}^{-1}$ which occurs at the fire growth stage for building structures. Further, the residual strength at cooling phase should be accordingly determined for each specified project condition. Therefore, number of tests have been carried out at Bergische Universität Wuppertal to investigate the effects of Polypropylene 


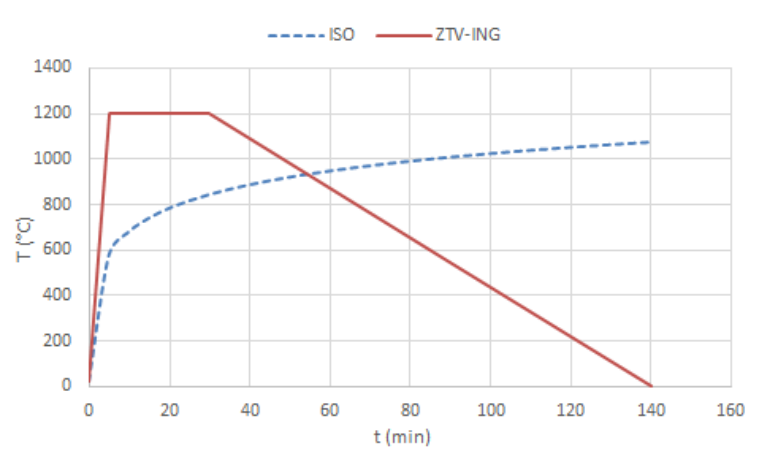

Figure 1. Nominal Fire Exposure Curve vs ZTV-ING Fire Exposure Curve [4.

fibres on material behaviour of concrete at high temperatures. For verification of Ultimate Limit States (ULS) criteria, structural calculations are performed for fire as an accidental design situation. In this case, the indirect thermal effects result from forces due to restrained thermal elongation or rotation dependent on the temperature distribution in the concrete cross section. The superposition of thermal effects in different time steps with the most unfavourable effects from standard load combinations is performed as so called thermo-mechanical analysis. This analysis is based on an iterative nonlinear calculation to determine the internal forces by considering the simultaneous decrease of stiffness of each cross section exposed to elevated temperatures, and considering the indirect thermallyinduced effects. The conditions of equilibrium and compatibility are met by taking into account the maximum permissible temperature-dependent strains for reinforcement and concrete given in EN 1992-1-2 [1].

To be able to analyse a 2 -cell cut-and-cover tunnel exposed to fire, an advanced analysis according to [1] has been performed by taking into account a model with a simplified boundary condition and nominal ZTV-ING Fire Exposure Curve [2].

\section{ZTV-ING Fire Exposure Curve FOR TUNnel STructures in Germany}

The most common fire exposure curve used for building fire structural design is the ISO fire exposure curve according to EN 1991-1-2 [1] whereas for road tunnels in Germany the ZTV-ING curve according to 2] has to be applied.

The tunnel shall be designed for the fire situation by considering the high possibility of several vehicles being involved in fire ignition and the fire rate of $100 \mathrm{MW}$ 5. Thus, the increase rate of temperature within the first five minutes from the start of ignition (Fig. 1) is very high. Further, for the long period of 25 minutes, temperature values remain constant, $1200^{\circ} \mathrm{C}$, which is completely different from the nominal fire exposure curve having a continuous trend where the ambient temperature reaches $1006^{\circ} \mathrm{C}$, gradually, after
90 minutes.

\section{Effects of Polypropylen FIBRES ON CONCRETE BEHAVIOUR AT ELEVATED TEMPERATURES}

The material properties according to EN 1992-1-2 [1] are based on the thermo-mechanical tests for the concrete without PP fibres and they correspond to the defined heating rate between 2 to $50 \mathrm{~K} \cdot \mathrm{min}^{-1}$. The latter is to be used for the structural calculations for tunnel structures having PP fibres in concrete's admixtures only conditionally due to the following reasons:

- The German Fire Exposure Curve for tunnel structures includes a cooling phase, which means it comprises a growth, a full and a cooling phase. Considering the latter, the changes in the strength of concrete in the cooling phase and the residual deformations are not considered

- The addition of PP Fibres has influence on the thermal and thermomechanical behaviour of concrete

Through the experimental investigation at Bergische Universität Wuppertal, influences of specific boundary conditions on the thermomechanical properties were investigated. These were conducted with steady and transient tests according to the recommendation of RILEM Technical Committee [6] on the test specimen with the diameter of $60 \mathrm{~mm}$ and the height of $180 \mathrm{~mm}$. For the samples, the concrete strength class of $\mathrm{C} 30 / 37$ with PP fibres and without PP fibres were used. A volume of $2 \mathrm{~kg} \cdot \mathrm{m}^{-3}$ of PP fibres has been added to the concrete mixtures to prevent spalling. Further, tests were carried out with drying boundary condition and moisture content of $3 \%$ at the beginning of test. To perform the compressive test a static compression and tension machine with a maximum compressive force of $250 \mathrm{kN}$ has been used. Heating has been performed via a tube furnace with a maximum temperature of $1200^{\circ} \mathrm{C}$. Two different deformation measuring devices were installed, one on the specimen and the other one on the test equipment. Regarding the material behaviour, the total strain suggested in EN 1992-1-2 is according to [7] and has the following components:

$\varepsilon_{t o t}=\varepsilon_{t h}(T)+\varepsilon_{\sigma}(\sigma, \sigma, T)+\varepsilon_{c r}(\sigma, T, t)+\varepsilon_{t r}(\sigma, T, t)$

Where $\varepsilon_{t h}$, thermal strain including shrinkage, $\varepsilon_{\sigma}$, instantaneous stress related strain, $\varepsilon_{c r}$, creep strain or time dependent strain and $\varepsilon_{t r}$, transient strain, all resulted from transient and steady tests. It should be noted that EN 1992-1-2, however, proposes an implicit model. To be able to model the behaviour of concrete by an explicit strain model, the transient creep component should be defined. Transient creep of concrete is the creep that occurs during first time heating at a constant rate under load. 


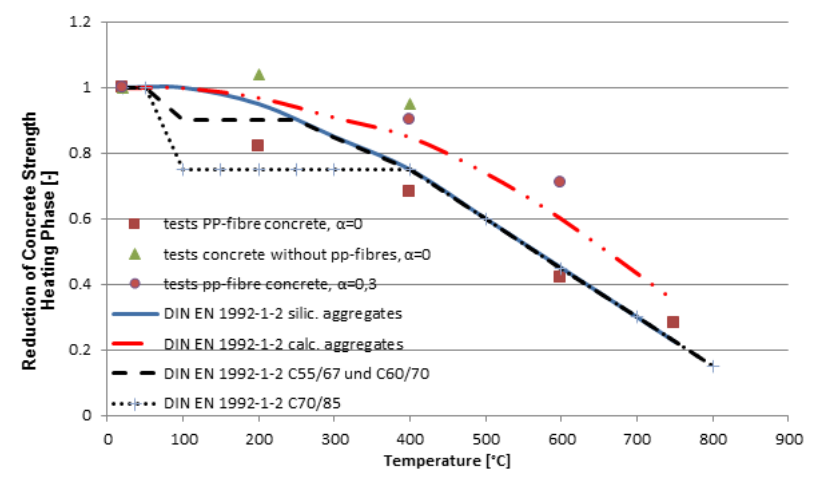

Figure 2. Comparison of reduction of compressive strength from the tests results with PP fibres with EN 1992-1-2 results for the specimen without PP fibres 9 .

Further for the drying boundary condition [8]:

$$
\varepsilon_{t r, c r}^{T, 0, d}=\varepsilon_{t r, t o t}^{T, \sigma, d}-\varepsilon_{t r, t h}^{T, 0, d}-\varepsilon_{t r, s h}^{T, 0, d}-\varepsilon_{c o, e l}^{T, \sigma, d}
$$

Where $\varepsilon_{t r, c r}^{T, 0, d}$, transient creep for drying concrete during heating, $\varepsilon_{t r, t o t}^{T, \sigma, d}$, total measured transient strain, $\varepsilon_{t r, t h}^{T, 0, d}$, thermal strain (free thermal strain), $\varepsilon_{t r, s h}^{T, 0, d}$, drying shrinkage strain and $\varepsilon_{c o, e l}^{T, \sigma, d}$, elastic strain. For drying concrete heated without load (i.e. $\sigma=0$ )

$$
\varepsilon_{t r, t h}^{T, 0, d}+\varepsilon_{t r, s h}^{T, 0, d}=\varepsilon_{t r, t o t}^{T, 0, d}
$$

Therefore:

$$
\varepsilon_{t r, c r}^{T, 0, d}=\varepsilon_{t r, t o t}^{T, \sigma, d}-\varepsilon_{t r, t o t}^{T, 0, d}-\varepsilon_{c o, e l}^{T, \sigma, d}
$$

Two main influences, rising from addition of PP fibres to the concrete mixture, are on the compressive strength of concrete evaluated from the steady state tests unstressed during the heating and on total transient strain, $\varepsilon_{t r, t o t}^{T, \sigma, d}$, for specimen under different stress levels, $\alpha$. The latter corresponds to the ratio of constant value of stress imposed during the heating phase to the compressive strength of concrete specimen at the ambient temperature. Results of steady tests as shown in Figure 2 from tests at 20, 200, 400, 600 and $750{ }^{\circ} \mathrm{C}$ compared to the test results from EN 19921-2 curves represents a good agreement between the compressive strength reduction of concrete specimen with PP fibres with a compressive strength of $63 \mathrm{MPa}$. Further, there is a considerable influence of loading on the reduction of compressive strength.

Figure 3 shows the values of thermal strains for concrete specimen with PP fibres. The results show that the addition of PP fibres has an influence on the thermal strain course. Thermal strains for PP fibres concrete in the range of $200{ }^{\circ} \mathrm{C}$ to $300^{\circ} \mathrm{C}$ shows a small amount of deviation compared to the values of EN 1992-1-2. Further, the maximum value of thermal strains for PP fibres concretes is lower compared to the EN 1992-1-2 curve. In range of 200 to $300{ }^{\circ} \mathrm{C}$ the drying shrinkage and thermal elongation components

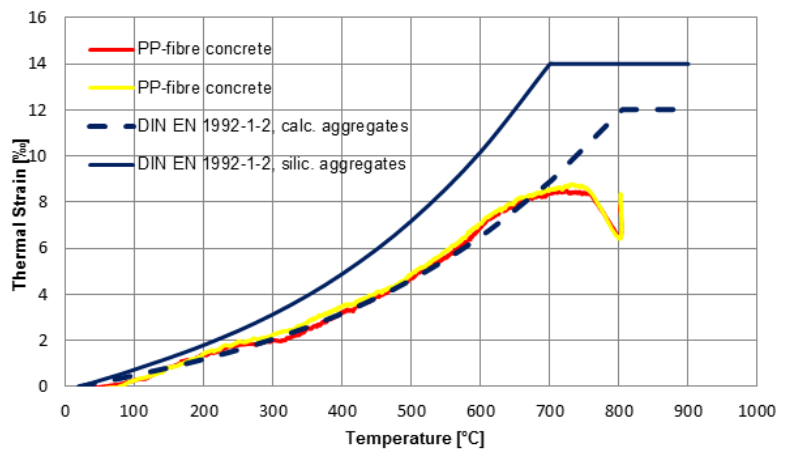

FiguRE 3. Total strain vs. temperature for specimen with PP fibres 9 .

are of main role and due to this there is not large deviation in this range. The lower value of maximum thermal strain for PP fibres concrete is due to a smaller crack divisions at PP fibres concrete and composition of less internal stress.

\section{Thermo-MeChanical Analysis}

In order to find the best approximation of heat transfer through the concrete elements, thermal analyses of five concrete samples with different thicknesses of 80 , $90,100,110,120$ and $130 \mathrm{~cm}$ have been performed for 90 minutes. Time intervals of 5 minutes, were chosen to read the absolute temperatures after each step. The absolute temperature values corresponding to each time interval are evaluated at different layers across the thickness of concrete. 1D heat transfer is considered by assuming concrete as a homogeneous and isotropic material. Fourier's law of heat conduction is used for the energy transfer in temperature gradients directions with the upper limit of thermal conductivity of concrete, $\lambda_{c}=1.951 \mathrm{~W} \cdot \mathrm{K}^{-1} \cdot \mathrm{m}^{-1}$, for the normal concrete corresponding to $10^{\circ} \mathrm{C}$ according to EN 1992-1-2. Further, absolute temperature values as a function of time according to ZTV-ING Fire Exposure Curve were applied on the exposed edges. The Newton's law of convection with the heat convection coefficients of correspondingly $\alpha=25$ and $50 \mathrm{Wm}^{2} \mathrm{~K}$ are used. The convective coefficient of heat transfer is, however, an experimental value and it is not a material constant. However, the comparison of results by the authors shows that using each coefficient influence the temperature fields in the fire growth phase for the fire exposed boundary up to 10 minutes by $5 \%$. Therefore, the effects are negligible in this range. To find the effect of emissivity $\varepsilon$ [10], studied two values of emissivity of 0.7 and 0.8 on the absolute temperatures within a concrete element and concluded that for the depth of $10 \mathrm{~cm}$ from the exposed surface there was a temperature difference of $10^{\circ} \mathrm{C}$ was observed and for the deeper layers there is no influence on the absolute values of temperature. Thus, Stefan-Boltzmann law is assumed with the emissivity grade of 0.8 . Figure 4 shows how temperature values vary as a function of time on 6 layers across the half-thickness of an $80 \mathrm{~cm}$ 


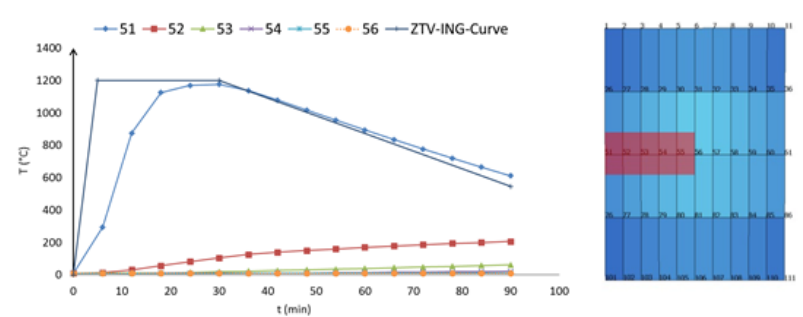

Figure 4. Temperature curves for an 80-cm-thick element at different nodes [1].

thick concrete element till 90 minutes. It is to be noted that temperatures on the boundary, corresponding to node 51, tend to increase with a slower rate compared to the temperatures according to ZTV-ING Curve up to 30 minutes.

Having thermal analysis performed for different concrete elements, the thermal effects are implemented to the mechanical model. This is performed by combining the multi-layered strain model [12], taking account of strain induced by thermal effects. The latter takes account of the reduced material strength corresponding to thermal and loading effects at each previous time step as initial governing state for the subsequent step of analysis. Based on 10-minute time intervals and nonlinear analysis, the stresses according to each time step plotted and the ultimate limit strength verification of the system for the whole duration of 90 minutes is carried out. The critical points at which the plastic hinges might be developed are identified and possibility of failure by developing further plastic hinges. By reaching 30 minutes, as shown in Figure 6 the maximum relative bending moment has reached a value of $-2514 \mathrm{kNm}$, approximately $73 \%$ greater than a moment imposed just after the ignition of fire (Fig. 5). This is due to the simultaneous increase of tensile stresses on the upper part of beam due to thermal induced bending moments and reduced cross sectional properties. The following parameters can affect the result of nonlinear analysis:

- time intervals chosen for thermal analysis (minor influence for intervals of 1 to 10 minutes)

- time intervals for load implementations (causes unavoidable inaccuracies for time intervals being larger than 2 minutes)

- Residual force tolerance at nodes (influences the convergence of FE solution and accuracy of effects of actions)

Mesh generation (influences both convergence and accuracy of results).

\section{Conclusions}

To be able to analyse a 2-cell cut-and-cover tunnel structure with a sufficient amount of PP fibres in the concrete mixtures, three main areas with the corresponding parameters, which can influence the results,

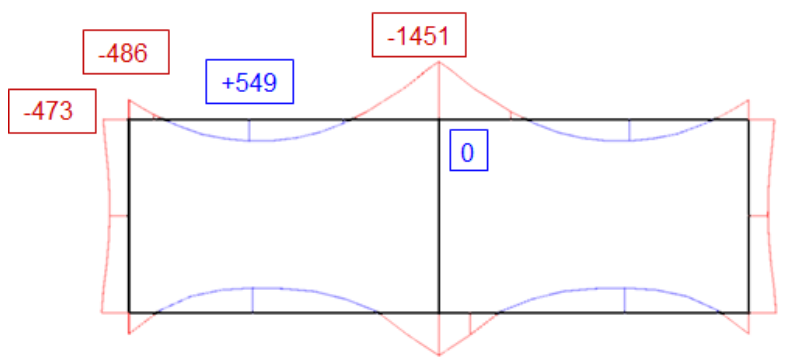

FiguRE 5. Bending moment diagram for $\mathrm{t}=0 \underline{4}$.

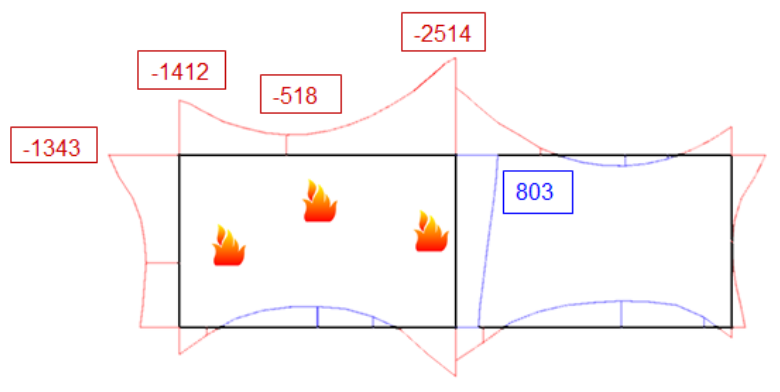

Figure 6. Bending moment diagram for $\mathrm{t}=30$ [4].

have been investigated. These main areas were defining a realistic fire action, using an appropriate material model and utilizing a thermo-mechanical model that can represent the nonlinear structural behaviour of the structure. The most important parameters according to each area were highlighted and discussed in this paper.

\section{ACKNOWLEDGEMENTS}

The paper has presented some global results from the research project "Verification the fire design of cut-andcover tunnel via nonlinear analysis", financed by BASt, and the results of test series carried out at the Bergische Universität Wuppertal. The support by BASt is gratefully acknowledged.

\section{REFERENCES}

[1] EN 1992-1-2: Design of concrete structures - part 1-2: General rules - structural fire design 2004.

[2] B. f. S. BASt. Zusätzliche Technische Vertragsbedingungen und Richtlinien für Ingenieurbauten (ZTV-ING). chap. 3, 5. 2013.

[3] K. Pistol, F. Weise, B. Meng. Polypropylen-fasern in Hochleisungbetonen. Beton- und Stahlbetonbau 107(7):476-483, 2012. DOI:10.1002/best.201200024

[4] O. Pouran, R. Harte, C. Peter. Nonlinear structural analysis of cut-and-cover tunnels exposed to fire. Applications of Structural Fire Engineering ASFE'15 2015. DOI:10.14311/asfe.2015.005)

[5] A. Schlüter. Passive fire protection for tunnels: Guidelines, parameters, reality and suitable measures. Tunnel pp. 22-23, 2014.

[6] Recommendation of RILEM TC-HTC: mechanical concrete properties at high temperatures-modelling and applications. Materials and Structures pp. 841-583, 2007. DOI:10.1617/s11527-007-9285-2 
[7] Y. Anderberg. Mechanical Behaviour at Fire of Concrete and Hyperstatic Concrete Structures. Lund Institute of Technology, Lund, 1976.

[8] RILEM TC 129-MHT: Test methods for mechanical properties of concrete at high temperatures recommendation: Part 7: Transient creep for service and accident conditions. Materials and Structures 31:290-295, 1998.

[9] C. Peter. Tragverhalten von Verkehrstunneln im Brandfall mit einer Innenschale aus PP-Faserbeton. Bergische Universitaet Wuppertal, Wuppertal, 2016.

[10] C. Peter, J. Knief, J. Schreyer, A. Piazolla.
Rechnericher Nachweis des baulichen Brandschutzes für Tunnel in offener Bauweise, Schlussbericht zum FE Projekt 15.0502/2010ERB im Auftrag des BMVBS/ der BASt 2013.

[11] O. Pouran, R. Harte. Prüfgutachten HH 02/14-1 zum Forschungsprogramm Straßenwesen FE

15.0582/2013/FRB Erprobung des rechnerischen Brandschutznachweises für Tunnel in offener Bauweise 2014.

[12] R. Harte, W. B. Krätzig, S. Y. Noh, Y. S. Petryana. On progressive damage phenomena of structures. Computational Mechanics 25:404-412, 2000. DOI: $10.1007 / \mathrm{s} 004660050487$ 